\title{
High-speed lines (HSL) as an environmentally friendly transportation system - the Polish case
}

\author{
W. Czyczula \& S. Lisowski \\ Faculty of Civil Engineering, \\ Institute of Road and Railway Engineering, \\ Krakow University of Technology, Poland
}

\begin{abstract}
Rapid growth of passenger traffic in Poland and other European countries is mainly observed on the road. This situation produces a strong environmental impact. Internal air transport in Poland is practically non-existent. For internal connections this transport mode probably will not play an important role in the future. It follows that only the rapid rail network should be taken into account when looking at ways to decrease of environmental impact.

In this paper the basic results of the study on the high-speed railway network in Poland are presented. There are four basic corridors: two in the east-west and two in the north-south direction. As a first stage the Warszawa-Katowice/Krakow High-Speed Line (HSL) should be taken into account. This line may be considered as a part of the VI Pan European Corridor. In addition, the conventional railway line Warszawa-Radom-KielceKrakow/Katowice will be in the same corridor.

The railway line Warszawa-Katowice/Krakow was designed as the main Polish line more than 30 years ago. The design speed was $250 \mathrm{~km} / \mathrm{h}$ and - partly $-200 \mathrm{~km} / \mathrm{h}$. Now the maximum operational speed is $160 \mathrm{~km} / \mathrm{h}$ only. The lack of adequate trains (especially locomotives) is one of the reasons for this situation. Amongst others are: the classical control system, the existence of 24-level crossings, etc.

A detailed technical and economical study is now being carried out. The paper presents the basic results of investigation on the Warszawa-Katowice/Krakow high-speed line. As a conclusion further investigations on the HSL network in Poland have been described.
\end{abstract}




\section{Introduction}

Development of a high-speed transeuropean railway system is one of the basic factors in the European transportation policy [2].

Based on the Directive 96/48/EC, the Technical Specification for Interoperability relating to the high-speed European network was prepared in 2002 (compare also [1]), the same documentation for conventional railways is now under preparation. It means that the high-speed railway network in Europe should be considered as the priority rail transportation system.

Since 1989 traffic on the high-speed railway network has continuously increased (see [4]). Now the total HSL European network (speed $\geq 250 \mathrm{~km} / \mathrm{h}$ ) consists of more than $3700 \mathrm{~km} \mathrm{[4].}$

The HSL European network is very effectively used - there are more than 20 million passenger-kilometers per $1 \mathrm{~km}$ of the line. In comparison: now in Poland the same passenger traffic factor is only about 1 millions passenger-kilometers per $1 \mathrm{~km}$ of the line (including the total railway network in service).

The high-speed line was first introduced in Japan. Now the Shinkansen network consists of more than $2300 \mathrm{~km}$ and is continuously increasing. Highspeed railways are also developed in USA, South Korea and Taiwan.

In contrast to the conventional railways, tramways and other light rail transportation systems, HSL are profitable. For example: in Spain the average income on the Madrid-Sevilla line in 2002 was equal to 0,02 Euro per one passenger-kilometer.

\section{High-speed lines and the environment}

High-speed trains use relatively high amounts of power. For example: trains with a weight of 400 tone moving at a speed $300 \mathrm{~km} / \mathrm{h}$ need more than $8 \mathrm{MW}$. This is high, but consider the international train Thalys:

- maximum power: $8,8 \mathrm{MW}$,

- number of places: 377 ,

- speed: $300 \mathrm{~km} / \mathrm{h}$.

Under the assumption that the maximum power of the traction unit is used and $80 \%$ of the places are occupied we obtain about $29 \mathrm{KW}$ per passenger. This value is comparable with a car occupied by two people. For a more general comparison between high-speed trains and cars the energy consumption per passenger-kilometer should be considered as the better factor.

Fig. 1 shows the use of energy and $\mathrm{CO}_{2}$ emissions for cars and high-speed trains per 100 passenger-kilometers.

From these data it follows that the emission of $\mathrm{CO}_{2}$ for high-speed trains is 3,5 times less in relation to passenger cars and energy use is 2,4 times less.

It means that from the point of view of the basic environmental factors, not only conventional but also high-speed trains are significantly better in relation to the cars.

The same results should be obtained if we consider the external costs of transport. 


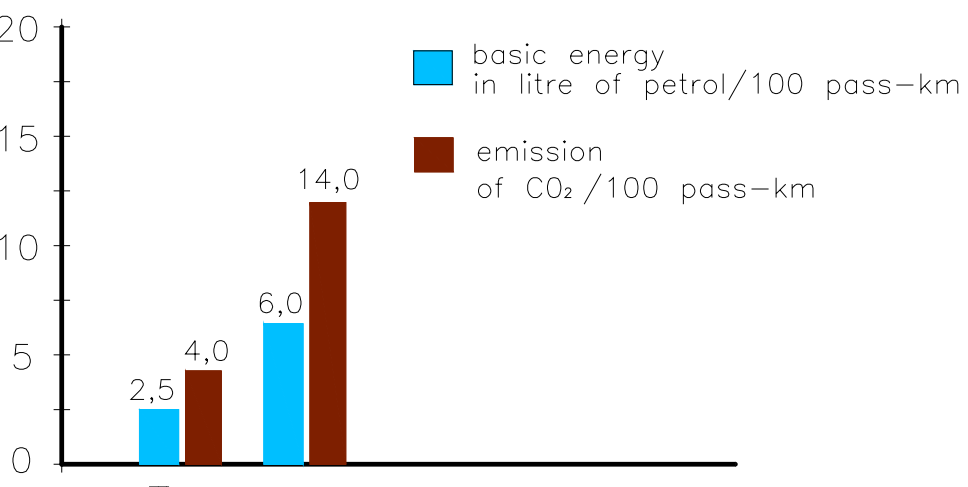

Figure 1: Emissions of $\mathrm{CO}_{2}$ and energy consumption for high-speed trains and passenger cars [3].

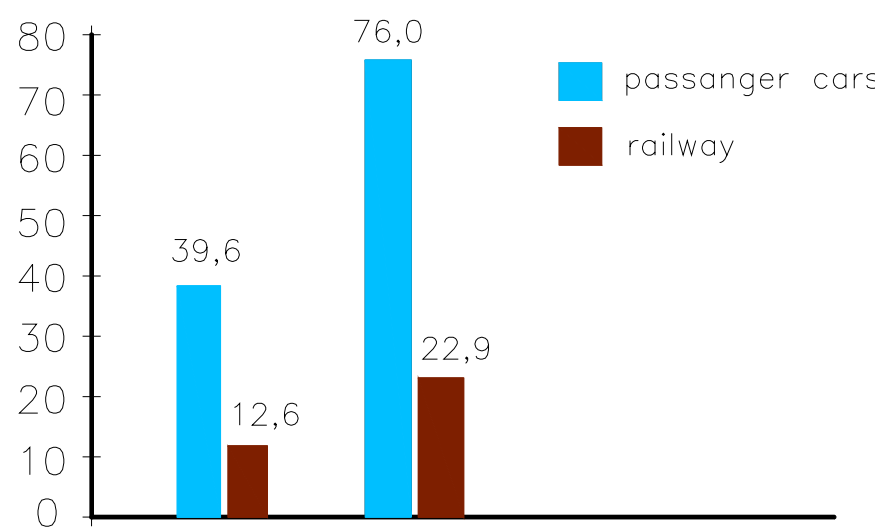

Figure 2: Comparison of the external costs of passenger transport in Poland and EU-15 (in Euro/1000 pass-km, without congestion cost).

If we consider only accidents in Europe in 2000 than we obtain the following factors (in number of deaths per 100 million passenger-kilometer):

- road (total, including cars, buses, truck, etc): 1,1,

- air: 0,08,

- railway: 0,04 . 
This value is valid for all railway transport, including conventional railways. High-speed operation is very safe: for example in the Shinkansen network since 1964 there has only been one accident not resulting in any deaths (this accident occurred due to the earthquake).

From the analysis it follows that - in contrast to many opinions - the highspeed railway transportation system is environmentally friendly, and gives the possibility for sustainable development.

\section{Possibility for development of the HSL in Poland}

Passenger traffic in Poland and other new EU countries may be described as follows:

- rapid growth on the roads,

- decrease of traffic on the railway (in Poland from 50,3 billion passenger-kilometers in 1990 to about 18 billion pass-km in 2005),

- rapid growth of air traffic, but only for international connections (internal air transport in Poland is practically non-existent).

Growth of road and air transport is typical for the whole of Europe but the decrease in railway traffic passengers in Poland is atypical (about 2, 8 times during 15 years).

In EU-25 railway traffic is stable and the high-speed operation covers more than $23 \%$ (in passenger-kilometers) and continuously increases.

If total railway traffic in the "old" EU members is also stable and high-speed traffic rapidly grows then conventional operations decrease.

Poland is a relatively large country: a population of 38 million, an area equal $312700 \mathrm{~km}^{2}$ and the distance from Warszawa to main cities is equal to $300-500 \mathrm{~km}$.

The question is how to break the rapid decrease in passenger rail traffic? If the adaptation of selected main line to the speed $160 \mathrm{~km} / \mathrm{h}$ does not break the rapid decrease in passenger traffic then we need try to introduce a high-speed operation.

The building of the new HSL is very expensive. In various conditions the cost of $1 \mathrm{~km}$ of line in Europe is equal to 6,3-19,6 million Euros. The high-speed train is also very expensive (from 15-29 million Euro per train [3]). Is it possible to build the HSL network in Poland now?

More than 30 years ago the railway line called CMK was built in Poland from Warszawa to Katowice with a connection to Krakow. From the geometrical point of view the line was designed on the speed $250 \mathrm{~km} / \mathrm{h}$ and - partly $-200 \mathrm{~km} / \mathrm{h}$. The basic parameters of the line are as follows:

- radius of horizontal curvature: $4000 \mathrm{~m}$,

- length of transition curve: $400 \mathrm{~m}$,

- maximum gradient: 0,6 percent,

- distance between the track axes: 4,5m,

- tunnels: none 
From the point of view of the Technical Specification for interoperability [1], the maximum possible speed of the train on this line is more than $300 \mathrm{~km} / \mathrm{h}$ and the distance between track axes is sufficient for the high-speed operation.

The line connects the regions with relatively large populations (see fig. 3):

- Warszawa - 1,7 million of inhabitants;

- Katowice and other neighboring cities: about 3 million;

- Krakow - 0,76 millions.

In the distance of $100-150 \mathrm{~km}$ to the south of Krakow there are the most popular tourist regions (mountains Tatra and Beskidy).

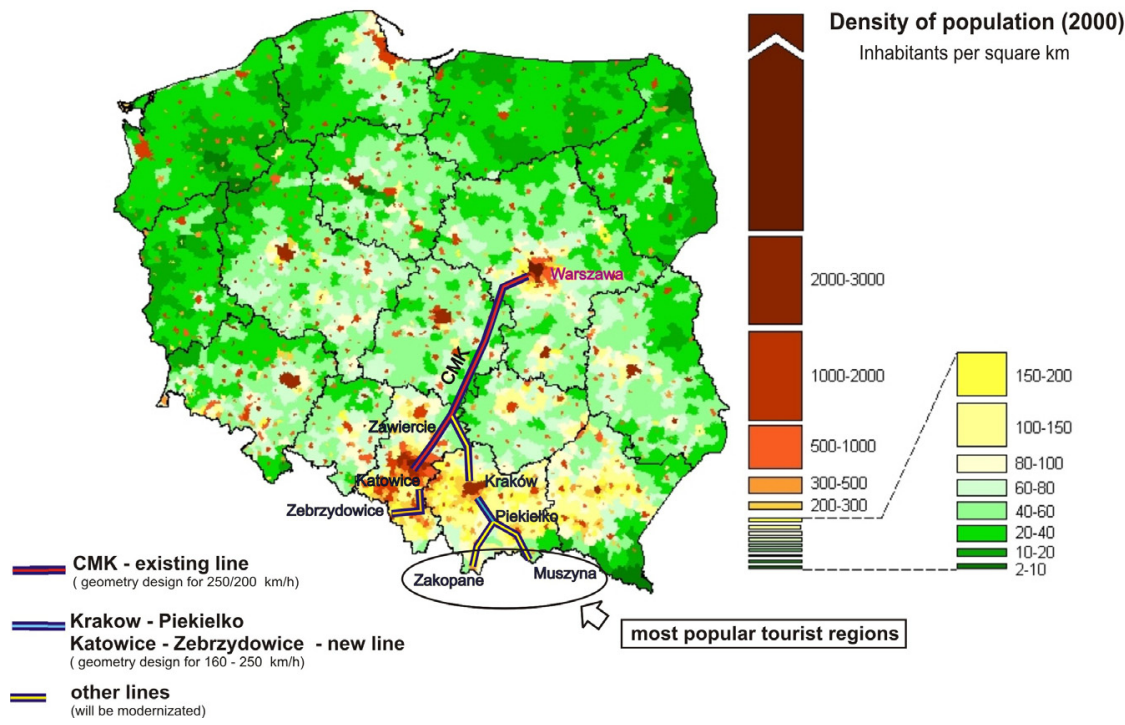

Figure 3: $\quad$ Map of the density of population in Poland with analyzed railway corridor.

It follows that CMK should be considered as a first step to introducing the HS railway network in Poland.

The following statements describe the basic work that should be taken into account:

1. Detailed analysis (feasibility study).

2. Investigation of the new track structure for the HSL in Poland (based on the Polish solution - fastening system and ballast).

3. Modernization of selected bridges and viaducts.

4. Building of in-collision crossings (there are 24 level crossing).

5. Building of a fence along the whole line.

6. Introducing a new control system.

7. Building - on part of the line - a new power system ( $25 \mathrm{kV} \mathrm{AC}$, in Poland $3 \mathrm{kV} \mathrm{DC)}$ 
8. New trains for the HS operation (multisystem, minimum $3 \mathrm{kV}$ DC and $25 \mathrm{kV}$ AC -15 trains, partly produced in Poland).

9. Modernization of a few locomotives for the multisystem operation.

The costs of these works are estimated at the following level:

1. Investigation, feasibility study, detailed technological design - about 15 million Euros.

2. Infrastructure work (only CMK) - about 160 million Euros (about 0,7 million Euro/km).

3. Rolling stock - 270 million Euros.

Other works should also be carried out:

- The modernization of the Zawiercie-Katowice and Psary-Kraków sections (in total $43 \mathrm{~km}+87 \mathrm{~km}$ );

- The modernization of the Warszawa-Kielce-Radom line as a part of the VI-th Paneuropean Corridor for conventional railway operation.

The described works should significantly decrease travel time from Warszawa to Katowice/Krakow: today this is $2 \mathrm{~h} 40-2 \mathrm{~h} 50$, in the future it will be about $1 \mathrm{~h} 40$ min. More details are shown in paper [5].

\section{Summary}

The high-speed railway operation should be considered as an environmentally friendly transportation system.

Basic factors, i.e. $\mathrm{CO}_{2}$ emissions and energy consumption per 1 passenger-kilometer are 2,4-3,5 times less in relation to passenger cars. It should be proved - based on European experiences - that the introduction of the high-speed operation will probably be an effective way to break the rapid decrease of railway traffic in Poland.

As the first step the CMK main line should be taken into account. This line needs only modernization without significant investment because its geometrical position was based on the speed of $250 / 200 \mathrm{~km} / \mathrm{h}$. Adaptation of this line for the speed of $300 / 250 \mathrm{~km} / \mathrm{h}$ needs less than 1 million Euro $/ \mathrm{km}$ in comparison to the 10-15 millions Euro/km for new line.

The basic HS network in Poland should consist of the following lines:

1. Gdansk-Warszawa-Kraków/Katowice (part of this CMK line) with the connection to Wien and Balkan countries including the Polish southern tourist regions.

2. German border (from Berlin)-Poznan-Lodz-Warszawa with the connection to the Belarusian border (to Moscow).

3. German border (from Dresden)-Wroclaw-Lodz-Warszawa.

4. German border (from Dresden)-Wroclaw-Katowice-Krakow with the connection to the Ukrainian border.

The development of the HSL in Poland needs a political decision: as described above, for the first CMK line including rolling stock only about 450 million Euro is necessary (equivalent to about $80 \mathrm{~km}$ highway). 


\section{References}

[1] Czyczula W., Infrastructure for high speed railway in Technical Specification for Interoperability (in Polish), Technika Transportu Szynowego, No. 5-6, p.73-79, 2005.

[2] White Paper, European Transport Policy 2010: time for decisions, EC, COM (2001), 370, 2001.

[3] Raczynski J., Massel A., Social and economic condition for development of high speed railways in Poland (in Polish), Technika Transportu Szynowego, 2005.

[4] EU Energy and Transport in Figures. Statistical Pocket book, 2005.

[5] Czyczula W., Concept of adaptation of CMK line to the speed 250/300 km/h with the modernization of the other lines in connection Warszawa Katowice/Krakow, Krakow University of Technology, Krakow 2006. 